\title{
Arquitectura de lo in-visible
}

.... de lo que no queremos ver

\section{Unseen architecture ... or of that we don.t want to see}

Hernando Carvajalino Bayona*

Citar este artículo como: Carvajalino, H. (2016) "Arquitectura de lo in-visible

...o de lo que no queremos ver". Revista Nodo, 10(20), pp. 55-64

\section{Resumen}

El presente artículo fue elaborado a partir de la presentación realizada por el autor en el marco del Seminario Internacional: "Los rostros del arquitecto, Las diversas formas de ejercer la profesión", organizado por la Asociación Colombiana de Facultades de Arquitectura (ACFA), en la Universidad Nacional de Colombia, Sede Bogotá, entre el 19 y 21 de marzo de 2014. La invitación se le extendió para que compartiera con estudiantes de arquitectura, la experiencia de vida, que como arquitecto de manera directa e indirecta ha mantenido con sectores sociales económicamente pobres, aunque ricos en otros aspectos de la vida, haciendo referencia al arquitecto como constructor de la comunidad olvidada.

Este texto se enmarca dentro de la categoría de documento de reflexión no derivado de investigación, sino, más bien, desde la mirada al quehacer que, como arquitecto, el autor ha tenido en el contexto de los barrios populares de origen informal, tanto en escenarios académicos como laborales.

\section{Palabras clave}

Arquitectura, barrio, comunidad, popular, social.

\section{Abstract}

This essay is based on a lecture made by the author for the International Seminar "The faces of the architect, the different ways of practice the profession", organized by the Colombian Association of Architecture Schools, presented at the Colombian National University (Universidad Nacional de Colombia) in Bogotá, between march $19^{\text {th }}$ and the $21^{\text {st }}, 2014$. The invitation was made to share with the students his direct and indirect experiences, as an architect, with communities economically poor, but rich in many other aspects. The main idea was that the architect can be a builder of the forgotten community. This document is not research, but the consideration about being an architect, has developed academically and professionally by the author while, working in popular and informal settlements.

\section{Keywords}

Architecture, suburb, popular neighborhood, community, popular, social.

Fecha de recepción: 15 de febrero de 2016 Fecha de aceptación: 28 de abril de 2016 Arquitecto, Magister en Urbanismo. Profesor de cátedra, Pontificia Universidad Javeriana y Universidad
Católica de Colombia. Director de Barrio Taller. $\underline{\text { hcb.barriotaller@gmail.com }}$ 


\section{Introducción}

Dentro de las distintas prácticas del quehacer del arquitecto, una de estas, ha tenido que ver con el compromiso con grupos sociales económicamente pobres, en particular, las que habitan en relación con nuestras ciudades en barrios populares de origen informal, conllevando un elevado compromiso social, en la búsqueda por mejorar las precarias condiciones habitacionales de núcleos familiares que viven habitualmente en la periferias urbanas.

Esta perspectiva, tanto académica como laboral, exige del arquitecto una reflexión profunda acerca de su papel en estos escenarios, en los que las problemáticas se multiplican, pero donde también surgen oportunidades que permiten plantear soluciones posibles, de la mano de la comunidad. Establecer unas relaciones más horizontales con los pobladores, adentrarse en sus dinámicas y lógicas del habitar, conocer su espacialidad y abrirse a espacios participativos, son tareas a asumir, en esta práctica alternativa de la disciplina.

El texto hace un recorrido reflexivo y propositivo, a partir de la experiencia que el autor ha tenido en este campo, planteando a los estudiantes de arquitectura, no sólo la posibilidad de considerar este posible campo de trabajo que pueden tener en la vida profesional, sino, también, planteándolo como una exigencia propia de esta disciplina, como parte de una deuda que se tiene con estos

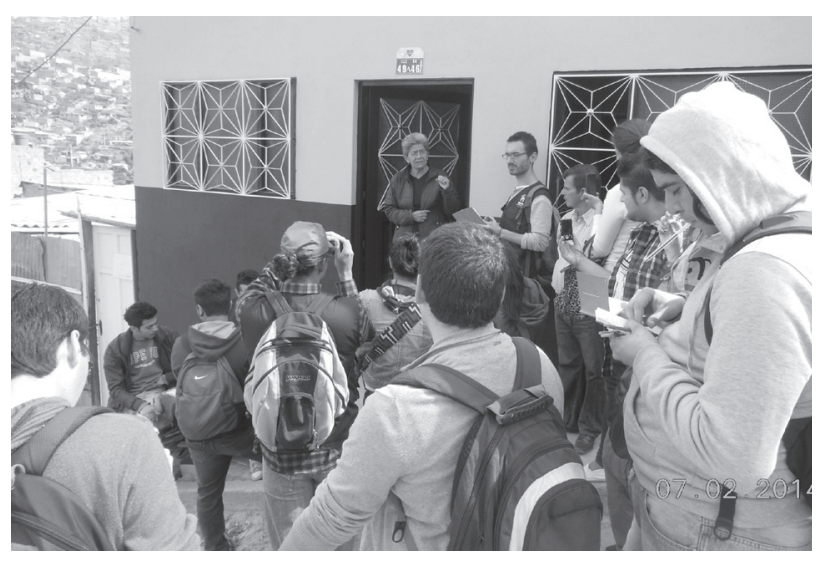

Foto: Hernando Carvajalino Bayona escenarios urbanos, y con un posible escenarios post-conflicto, si se revisa en positivo la posibilidad futura de que se suspenda en definitiva la espiral de violencia que genera el conflicto armado y social que vive nuestro país, escenario que nos obliga a futuro como arquitectos a vincularnos creativamente a esta problemática, la del hábitat popular.

\section{Preguntas fundamentales, al salir de la universidad}

Para iniciar, he considerado pertinente este texto del escritor Mario Mendoza, encontrado en un periódico del año 2007, en el que plantea lo siguiente:

He comprobado muchas veces a lo largo de los años, que en ciertos ámbitos intelectuales y académicos hay un rechazo visceral hacia lo popular. Lo consideran algo menor, una especie de preocupación alejada de reflexiones elevadas y trascendentales. Por lo general, esta élite intelectual cerrada y de gustos extranjerizantes repite a nivel estético los mismos vicios que su clase social practica a nivel político: la exclusión, la segregación, el racismo, la intolerancia, el miedo a una auténtica democracia participativa ${ }^{1}$.

Reflexión que nos invita a cuestionar qué tan distantes estamos de ésta, al interior de nuestras facultades de arquitectura.

Partiendo de esta primera mirada crítica que nos sirve de contexto, aproveché entonces para hacer un repaso de mi recorrido como arquitecto, en estos treinta años de vida profesional. Imaginemos entonces a un joven de veintitantos años, como ustedes, saliendo de las aulas universitarias, con el título de arquitecto bajo el brazo, preguntándose qué hacer en adelante. Surgían entonces, las posibilidades laborales de siempre, pero también,

1 Mendoza es escritor y profesor universitario, ha publicado entre otros, los siguientes libros: Scorpio city, Buda blues y Satanás. 
los sueños e ideales de hacer algo distinto, en un momento histórico, en el que estos otros caminos por descubrir subvertían la línea recta a seguir, para la cual nos habían formado.

Era entonces de una apuesta personal frente a un mundo que consideraba injusto, al cual quería aportar algo desde mi disciplina, algo distinto al quehacer tradicional del arquitecto, queriéndome involucrar a estas otras dinámicas que tenían como centro a grupos sociales económicamente pobres, al poblador y a la comunidad, en un contexto renovado y contestatario, en el que la utopía de transformar el mundo parecía estar al alcance de nuestras manos.

Salgo graduado a mediados del año 1983, la mayoría de ustedes ni siquiera había nacido y me preguntaba entonces: ¿Cómo involucrar la arquitectura a esta otra realidad? La de los barrios populares, que en los extramuros se venían conformando. Debí entonces, involucrarme en los laberintos de la realidad social y en su irremediable conexión con nuestra disciplina y preguntarme ¿En qué país vivimos? ¿En qué ciudades? ¿Tenemos algún compromiso social con estos escenarios? ¿Con qué espíritu crítico nos formaron en las facultades de arquitectura, en relación con estos problemas? ¿Vamos como arquitectos a seguir siendo ajenos a esta situación?

Estas preguntas rondaron en aquel entonces y me obligaron a ahondar en las problemáticas de ese momento y a buscar respuestas en los libros, en conversaciones con arquitectos que habían tomado aquel camino, en ONG que ya venían trabajando estos temas y a buscar contacto con otras disciplinas distintas a la arquitectura, las disciplinas sociales.

Esos son arquitectos a los que les gusta "jugar a ser sociólogos", eran algunos de los primeros señalamientos que empezaban a hacerse desde la misma disciplina, al no ser bien vista aquella búsqueda de una práctica alternativa para la arquitectura. Y mucho menos, metidos en esos escenarios, que desde la tecnocracia, eran vistos como una especie de "cáncer urbano", el cual había que extirpar, nada había que ir a hacer allí, mucho menos a aprender algo de ellos, decían algunos.

No obstante, y siguiendo en contravía, el camino más práctico a tomar sería acercarme de manera directa a los barrios populares, paso inmediato a seguir, en donde empezaría a encontrar respuestas a buena parte de estas preguntas. Cómo hacerlo, he ahí la búsqueda de nuevos territorios por explorar, los cuales, como veremos más adelante, irían apareciendo.

\section{Experiencias vitales, recién comenzando la práctica profesional}

En los barrios populares de origen informal tradicionalmente ubicados en los extramuros de nuestras ciudades-, los pobladores han incidido directamente en la conformación de su hábitat - sin contar con profesionales en este campo- a través de la lucha diaria por un cobijo, por un techo. Y si bien no han tenido la instrumentación técnica, ni la necesaria conceptualización espacial, sí tienen un conocimiento que les ha dado la experiencia y el espíritu de sobrevivencia que exige el resolver, aunque de forma precaria, sus problemas cotidianos.

Con este planteamiento no se quiere proponer una visión populista, en el sentido de sobrevalorar el contenido de estos territorios urbanos, ni mucho menos aportarlo como ejemplo de pensamiento, ni de construcción de ciudad posible, ni ideal. Más bien, entenderlo como un territorio real, diferente y heterogéneo, a abordar desde la arquitectura.

En estos escenarios se levanta una ciudad en proceso de consolidación, una ciudad inacabada, en la cual se concentran graves problemas habitacionales, propios de una sociedad inequitativa. Allí, se han construido viviendas y barrios que no se han valorado en toda su dimensión, levantados con las propias manos de sus pobladores. Ellos han venido participando a su manera, desde lo cotidiano, y hemos sido más bien los arquitectos, quienes 
hemos estado ausentes y es a quienes debemos invitar para que se aproximen a estos otros escenarios, que apenas tangencialmente abordamos desde las aulas universitarias. Desde la arquitectura se deben abordar, entre otros, proyectos encaminados a mejorar lo construido y a apoyar procesos de producción social del hábitat como posibilidad de elevar colectivamente las condiciones habitacionales de estos asentamientos.

Volviendo a mi recorrido personal, en aquel momento me acerqué a la lucha que por un techo estaba dando un sindicato de transportadores que dio pié a un asentamiento de vivienda que se comenzaba a gestar en uno de los extremos de la ciudad, el barrio El Motorista de Bosa, al sur de la ciudad, y casi de forma paralela, a un proceso de autogestión comunitaria que otro grupo de pobladores adelantaba en el otro extremo, en el norte de la ciudad, en terrenos en los que se ubicaría el barrio Unicerros.

En el barrio El Motorista, aprendí en vivo y en directo, del esfuerzo colectivo de un grupo de trabajadores que luchaban por sus derechos laborales. De forma paralela me fui dando cuenta la forma en la que, de manera espontánea y sin arquitectos, estos trabajadores fueron conformando su propio asentamiento, a través de la lucha por un techo, por un cobijo. Solidaridad, posturas políticas, esfuerzos colectivos y autoconstrucción, fueron elementos que fui descubriendo, y también, como se movían en estos escenarios grupos culturales que apoyaban a niños, jóvenes y madres comunitarias, en improvisados salones comunales de latas y cartón, y me encontré con estudiantes de psicología social comunitaria, que llevaban bajo el brazo libros de investigación acción participativa (IAP) y de educación popular. Autores como Orlando Fals Borda y Paulo Freire, eran los más leídos ${ }^{2}$, estos me permitieron permear la formación técnica, abriendo ventanas a la posibilidad de

2 Dos de los textos más estudiados en aquel momento eran El problema de cómo investigar la realidad para transformarla (1978) de Orlando Fals Borda y Pedagogía del oprimido (1970), de Paulo Freire. empezar a entender estas otras lógicas y maneras distintas de habitar.

En esta búsqueda, encontré entonces que otros arquitectos que no me habían mencionado en la universidad andaban siguiéndole los pasos a los pobladores, a través de algo que en su momento llamaban la "arquitectura descalza", haciendo referencia a aquel sector de la disciplina que estaba comprometida con grupos sociales económicamente pobres.

Un primer referente, fue el del urbanista Robert Goodman a través de su libro ¿Después de los urbanistas qué?, este discurso contestatario y radical, me abrió más los ojos para re-pensar desde mi propia historia de vida, el papel que debía asumir en adelante. Así mismo, profundicé en otros autores como Christopher Alexander, Giancarlo de Carlo y Lucien Kroll, entre otros, quienes venían concibiendo y poniendo en práctica procesos participativos, con los futuros usuarios de sus proyectos.

Y a nivel local fueron muy importantes los contactos que tuve con los arquitectos Roger Katan, Francisco Jiménez Velásquez, Oscar Becerra y Walter López, proceso que para ese momento adelantaba con el arquitecto Avendaño Triviño, con quien había egresado recientemente de la misma Universidad La Gran Colombia.

Para esa época, con el arquitecto Avendaño, con el riesgo y la iniciativa a flor de piel, propia de un par de jóvenes arquitectos, estructuramos un método de trabajo propio ${ }^{3}$ en el que, a través de talleres con la comunidad, nos lanzamos a producir nuestra propia versión del diseño participativo y de ponerlo en práctica en el otro proyecto que ya había mencionado, el del barrio Unicerros al norte de la ciudad.

3 En aquel momento (1985), como fruto de un trabajo de investigación en el Centro de Investigaciones y Servicio Social de la Facultad de Arquitectura de la Universidad La Gran Colombia, se elaboró el documento "Modelo teórico práctico para la participación comunitaria en el diseño", el cual sirvió de guía metodológica para el proceso que se adelantó en el barrio Unicerros. 


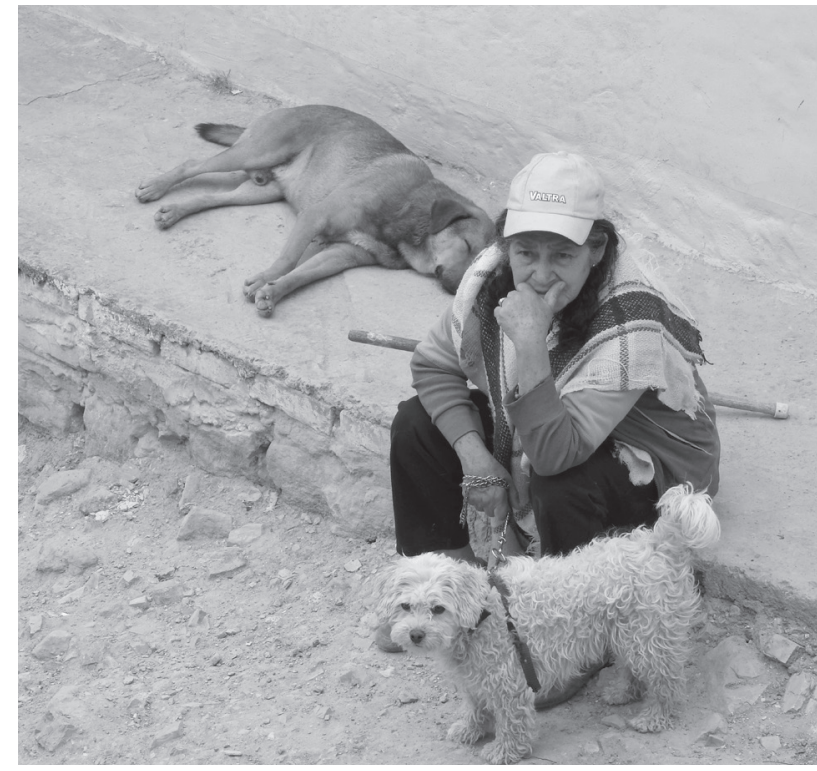

Allí, en Unicerros, un grupo de cien familias desarrollaba un proceso complejo de autogestión comunitaria a plenitud, sin apoyo del Estado, ni de la empresa privada, compraban un predio con esfuerzos propios, mediante bazares, rifas y ahorros, con un trabajo comunitario intenso los fines de semana y apoyados por un par de arquitectos que decidieron acompañar un proceso de diseño participativo mediante talleres con la comunidad -lo que constituía todo un diálogo de saberes-, en los que se apostaba por el entendimiento de esas otras lógicas de habitar, un cúmulo de experiencias comunitarias, en donde la arquitectura se hizo presente. Posteriormente, la misma comunidad fabricó los bloques de cemento en el sitio, extrajo materiales para la construcción de lugares cercanos y adelantó por completo la autoconstrucción de las viviendas, hombres, mujeres y niños, como hormigas formaron parte de este proceso colectivo para hacerse a un techo.

Hace unos pocos días, cuando fuimos de nuevo a visitar el lugar con una profesora y algunos estudiantes, después de muchos años de no estar por allí, nos encontramos con un barrio mucho más consolidado, y a mi manera de ver, de una calidad urbana y arquitectónica mucho más elevada que la mayoría de los barrios populares de la ciudad, e incluso, por encima de urbanizaciones de vivienda social producidas por el sector formal. Además, y quizás lo más importante, encontramos a una comunidad orgullosa de sus logros través del esfuerzo colectivo. Es gratificante esta experiencia en la que pudieron confluir el saber popular de los pobladores y el saber académico que se aportó desde nuestra disciplina.

Hasta aquí mi referencia a estas experiencias iniciales, reiterándoles que fue un aprendizaje intenso y permanente, desde abajo, desde la base, desde las comunidades de este par de barrios que complementaron profundamente mi conocimiento de la arquitectura, fueron ellos nuestros maestros, no solo de obra, sino, maestros de la vida, pues de ellos aprendimos mucho de lo que hoy sabemos de arquitectura popular y de la vida.

\section{Rentabilidades múltiples como concepto desde lo laboral}

Alguna vez en la Facultad de Arquitectura de la Universidad Nacional de Colombia, por allá comenzando los años noventa, nos reunimos varios colectivos de trabajo que desde la arquitectura trabajábamos en la periferia y después de discutir varios temas que nos convocaban en aquel momento, surgió una inquietud por parte de alguno de los participantes, relacionada con la comparación entre el amplio número de familias de los barrios que se habían beneficiado con nuestro trabajo en el mejoramiento de su barrio y de su vivienda, y la pregunta que de forma capciosa formulaba alguno de los asistentes, acerca de cuántos de nosotros, como arquitectos, teníamos solucionado nuestro problema de vivienda, o más bien, cuántos de nosotros vivíamos aún con la familia o pagábamos arriendo. Al mirarnos unos a otros, nos dábamos cuenta que éramos la mayoría, casi todos, los que no teníamos resuelta nuestra vivienda. Esta anécdota reflejaba aquel ideal comunitario de compromiso social, incluso de romanticismo o compromiso ideológico, mediante el cual eran los pobladores los únicos 
protagonistas, y nosotros como asesores, con nuestros intereses particulares, pasábamos a un segundo plano. Cuestionamiento puramente pequeñoburgués señalarían algunos en aquel momento.

Después de trasegar por varias ONG, dedicadas a trabajar en estos barrios, y sin dejar en el olvido aquella conversación, surgió la idea de estructurar un colectivo de trabajo, que tuviera como meta el seguir brindando asistencia técnica integral a procesos habitacionales populares, pero con un componente nuevo, que el proyecto fuera rentable económicamente y sostenible en el tiempo.

Esta idea, por allá en 1989, hace ya un poco más de veinticinco años, nos llevó a fusionar dos palabras, dos conceptos BARRIO + TALLER, el barrio como contexto de trabajo y el taller, rememorando el espacio académico de nuestra formación como arquitectos, y también el espacio productivo que repetidamente encontrábamos en los barrios, de allí surgió nuestro colectivo de trabajo BARRIO TALLER, el cual constituimos como sociedad limitada, con ánimo de lucro, distanciándonos del carácter de las ONG que sin ánimo de lucro en aquel momento, en su mayoría, eran financiadas con recursos de agencias internacionales para el desarrollo.

Entonces, con el tiempo, a sabiendas que de entrada había una clara RENTABILIDAD SOCIAL de nuestro trabajo en los barrios, debimos estructurar de forma paralela la RENTABILIDAD ECONÓMICA, pues de lo contrario no podríamos sostenernos en el tiempo. No contentos con lo anterior, sumamos otro concepto adicional, el de RENTABILIDAD ACADÉMICA, pretendiendo producir conocimiento en torno al campo en el que trabajábamos, y además, llegar a publicarlo.

¿Cómo obtener estas RENTABILIDADES MÚLTIPLES trabajando en un escenario económicamente pobre? Tal era el reto que nos proponíamos: pasar del quehacer espontáneo a otro ligado de forma más estrecha con las reglas del mercado, lo cual no dejaba de ser contradictorio y riesgoso, pues era pensar en montar empresa, en un contexto tan complicado como éste, pero esa fue nuestra apuesta.

Una necesidad evidente en estos barrios era la consolidación de la vivienda en el tiempo, concepto que John Turner acuñó como desarrollo progresivo por allá en los años setenta. Y para alimentar este proceso, nos juntamos al comenzar los años noventa diversos colectivos de trabajo, y junto a una cooperativa estructuramos un programa de crédito solidario que permitía a estas familias habitualmente rechazadas por el sector financiero tradicional, acceder a créditos para invertir en la vivienda y contar de forma paralela con una asistencia técnica que permitía mejorar el proceso de diseño y construcción de la vivienda.

Considero que de esta fase fue relevante la construcción colectiva de metodologías de trabajo en torno a procesos de mejoramiento barrial y de vivienda. Inicialmente apalancados con créditos cooperativos, y posteriormente con subsidios de vivienda y de entorno que el gobierno nacional formularía en sus políticas de vivienda, como respuesta al elevado déficit de vivienda que se acumulaba en el país, nuevos escenarios de trabajo que surgirían en los años noventa.

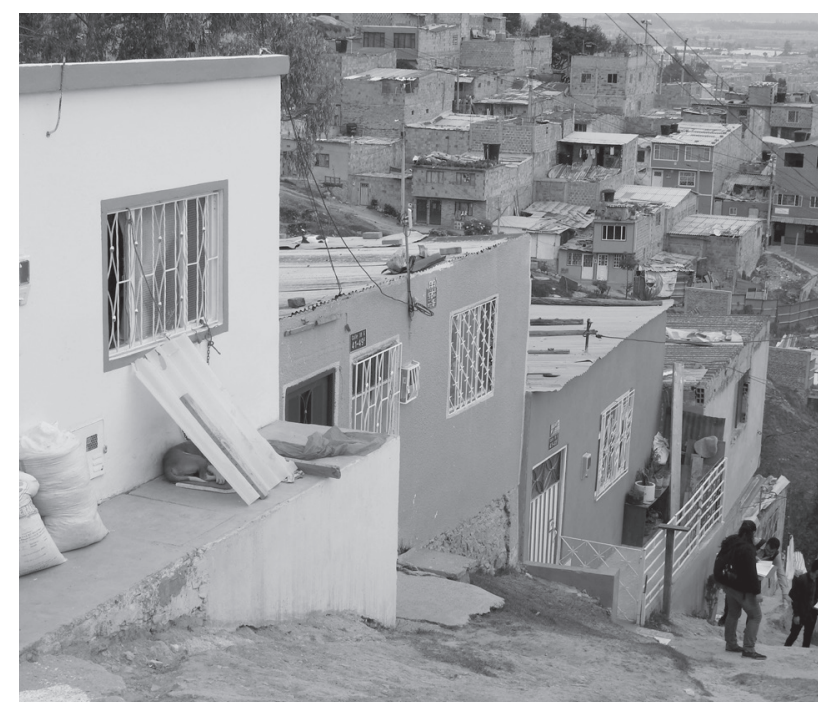


De acuerdo con los datos procesados por la Subdirección de Gestión Urbanística del Departamento Administrativo de Planeación Distrital, año 2002, Bogotá presentaba un total acumulado de 1.374 asentamientos de origen ilegal, en los cuales se refugia una población de 1'372.436 habitantes. Estas cifras evidencian un fenómeno de gran impacto urbano, pues el $22 \%$ de la población urbana se aloja de manera ilegal y ocupa cerca de un $21 \%$ del área total de desarrollo de la ciudad. Un informe técnico de la Secretaría Distrital del Hábitat (2008), hacía referencia de un potencial de 126.643 unidades de vivienda, que podrían construirse sobre las terrazas de las viviendas de un piso -autoconstruidas por los pobladores-, las cuales deberían ser sujeto de mejoramiento previo, tanto a nivel estructural como de condiciones de habitabilidad.

En este nicho de trabajo nos hemos desempeñado los últimos años, y en ejercicios de consultoría en este mismo campo. Hemos pasado este tiempo, como dice la canción del cantautor argentino Víctor Heredia, sobreviviendo. Lamentablemente, han sido muchos los colectivos de trabajo que han desaparecido; afortunadamente han surgido otros tantos.

Y qué decir, finalmente, de la rentabilidad académica. La publicación de doce volúmenes de la Serie Ciudad y Hábitat, durante trece años, es el aporte que dejamos en este campo, documentos hoy a disponibilidad de ustedes, a través de nuestro sitio web (www.barriotaller.org.co). De este trabajo se destaca la investigación "Espacialidad de la periferia" ${ }^{4}$, a través de la cual nos aproximamos de forma sistematizada a esa arquitectura sin arquitectos que a nivel de la vivienda producen los pobladores, trabajo académico que recibió Mención de Honor en la Bienal de Arquitectura 2002, en el Capítulo de Teoría e Historia.

$4 \quad$ Esta investigación se realizó con el apoyo de una Beca del Ministerio de Cultura, al fomento a la creación y la investigación en artes, ciencias sociales y comunicaciones, otorgada en el año 1997, y fue publicada por la Serie Ciudad y Hábitat, de Barrio Taller, en el año 2000.
Así mismo, a nivel de reconocimientos recibimos sendas Menciones de Honor por parte de la Federación Panamericana de Asociaciones de Arquitectura en el año 2008 en el Capítulo Hábitat Popular, y por parte del Consejo Profesional Nacional de Arquitectura, en reconocimiento a la responsabilidad social, en el año 2011.

\section{Fisuras en la academia, apuntes desde las facultades de arquitectura}

Si bien comencé a vincularme a la academia, casi de forma paralela a como lo hice con los barrios populares, ha sido en estos diez últimos años que he llegado a madurar todas aquellas ideas que desde muy joven empecé a elaborar en la Universidad La Gran Colombia y de forma pasajera en las universidades Piloto y Los Andes. Allí empecé a dar los primeros pasos como profesor e investigador, pero sobre todo a descubrir y a aprovechar las fisuras que la academia me permitía para actuar en estos escenarios, que, aunque escasas, eran una oportunidad en aquel momento.

En ese sentido la experiencia académica de esta última década en las Universidades Javeriana y Católica, las cuales me han brindado espacios muy amplios para trabajar en conjunto con otros profesores y con estudiantes en barrios populares, sobre todo en la aproximación de nuevas generaciones a estos asentamientos, y desde allí, conocer las otras dinámicas urbanas y arquitectónicas que se presentan, pero además, conocer desde lo social y lo cultural, aquellas manifestaciones que se presentan a través de la relación más cercana, horizontal y respetuosa con los pobladores.

No obstante, en el ámbito académico, si bien se han ganado espacios para abordar estos trabajos en las facultades de arquitectura, aun desde mi punto de vista, siguen siendo experiencias aisladas si se comparan con la dimensión del déficit habitacional del país, en particular la del déficit cualitativo, el de los barrios populares. Se requieren más profesores y estudiantes al frente de esta monumental tarea. 
Con el paso de los años y como sumatoria de este cúmulo de conocimiento, que semestre a semestre vamos sumando, se ha avanzado en propuestas metodológicas en favor de mejorar lo construido, desde la perspectiva de cómo aproximarse a estudiar estos asentamientos, de profundizar en sus problemáticas, y también, en sus oportunidades, para formular propuestas de mejoramiento de barrios desde lo público y lo colectivo, y necesariamente desde lo habitacional, de la casa, de la vivienda.

Si bien todavía existe sobre las mesas de trabajo la tentación de la "operación bulldozer", y arrasar con estos barrios, pasando por encima de esta producción social del hábitat, que los pobladores, individual y colectivamente han concebido $y$ construido a su manera, existe el día de hoy cierta conciencia por respetar lo existente, aproximarse al poblador y optar por mejorar y potenciar lo que al día de hoy se ha construido.

$\mathrm{Al}$ respecto, es pertinente, esta cita de Montaner:

Cada vez que se arrasa la vida comunitaria y el patrimonio existente, se produce un proceso de impostación de una falsa memoria sobre la memoria que había existido. Es un valor reconocido que los grandes operadores financieros e inmobiliarios exigen terrenos en su estado óptimo: habiendo borrado toda construcción en él para poder implantar una ciudad genérica y homogénea. $\mathrm{Y}$ aunque se admite que este borrado sistemático de culturas y memoria crea heridas físicas y psicológicas en la población, se considera que es un mal menor o un efecto colateral que se exige sea asumido (Montaner, 2004).

No en vano el sector inmobiliario, según información reciente, ya está llegando a estos barrios para comprarlos y elevar en estos, una vez demolidos, no solo sus enormes torres y edificios, sino sus incalculables utilidades económicas, irrumpiendo de forma agresiva en estos lugares.

En contravía a todo esto, en la academia seguimos teniendo tiempo para soñar, y para avanzar así sea tangencialmente, sobre los pasos de animal grande

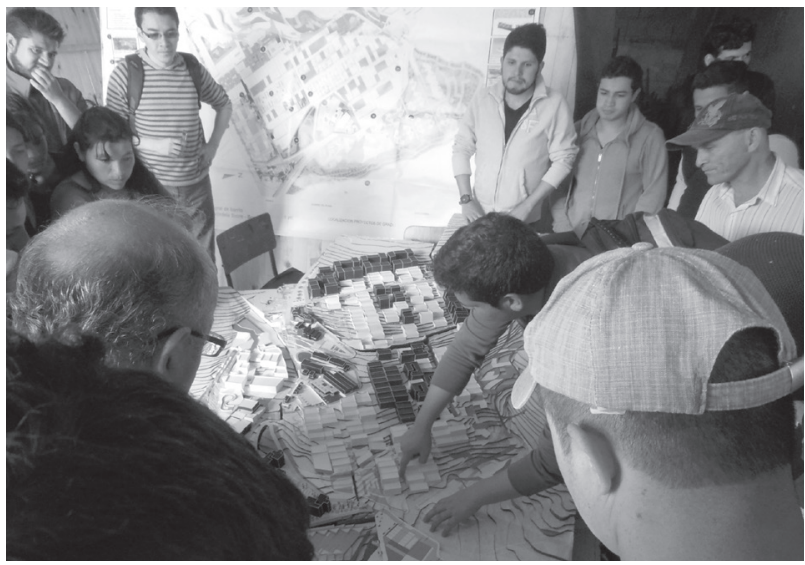

que nos impone las leyes del mercado y el sector inmobiliario. En ese sentido, traigo a colación una frase que escuché de un colega amigo, el arquitecto López, respecto a este tipo de prácticas que van en sentido contrario a los del mercado, señalando que "una pulga no para un tren, pero llena de ronchas al maquinista".

Al día de hoy, al abordar desde la academia estos escenarios, de manera gratificante puedo decir que resulta maravillosa la manera en que los estudiantes se vienen aproximando a los barrios populares con un interés grande, sincero y comprometido. Y que pasados los días de estar involucrados en estos procesos, descubren en esa producción social del hábitat, la gestión solidaria que se evidencia al consolidar el barrio y su vivienda, entendiendo que en esos asentamientos asimilados por los medios de comunicación como territorios de miedo, hay innumerables gestos solidarios por descubrir. Entonces, desde la disciplina se dan cuenta que esas casas que no se repiten una tras otra, como las que hacemos desde la arquitectura, son diversas, no son iguales unas a otras, tienen programas arquitectónicos múltiples, así tengan patrones en común.

Así mismo, que estas no se hacen en un solo momento, sino por partes, por etapas, como lo decía alguna vez un poblador se hacen "paso a paso, peso a peso, piso a piso..., progresivamente, como nos lo planteó Turner (1977) hace ya varias décadas. Y entienden además, que la casa no solo 
se habita, pues la premura económica, obliga a que la casa sea tienda, sea taller, que sea una vivienda productiva. Y que desde lo público, la esquina, la calle y la cancha, son tan importantes, como el parlante del barrio. Y ni qué decir del engalle de la casa como manifestación de esa cultura popular, de ese diseño de sus fachadas de las que cuelgan texturas y colores, estrellas y rombos, una vez esta se va consolidando con el paso de los años.

Se le plantean entonces, al urbanismo y a la arquitectura, nuevos retos, en el sentido de una mayor apertura a otros conocimientos. Borja \& Castells, (1999) proponen al respecto que "nadie tiene el monopolio del saber urbano, pero todos tienen fragmentos necesarios para construir la ciudad. No se trata de colocar un fragmento al lado del otro, sino de combinarlos según las posibilidades de cada momento y de cada espacio"; exigiendo de paso, una mayor aproximación a la realidad urbana, agregando luego que:

Para transformar la ciudad hay que conocerla. Las ciudades se conocen con los pies. Para proponer programas viales y sistemas de transporte hay que andar la ciudad y mezclarse con sus gentes. El urbanismo no trabaja en un laboratorio sino en la calle, no se traslada todo el tiempo en coche sino que salta de un medio a otro, no habla solamente con colegas y profesionales, sino con las diversas personas que viven la ciudad. Hay que pisar en algún momento cada barrio y cada obra y entrar en las casas y hablar con la gente. Transformar la ciudad supone un estilo de vida (Borja \& Castells, 1999).

\section{Conclusiones, a manera de reflexión}

Saliendo por las puertas de la universidad y entrando a los zaguanes del barrio popular, tomé este camino como proyecto de vida, con el cual me he desarrollado como persona y como arquitecto. La forma en la que intenté plantearlo ante ustedes en esta tarde resulta importante en tanto es necesario, desde un principio, asumir una posición crítica frente a la vida, y a partir de preguntas medianamente inteligentes buscar caminos alternativos. Hoy, treinta años después, ha sido muy gratificante el haberlo escogido, con todas las luces y sombras encontradas en este camino, permaneciendo aquí, en esta especie de trinchera, con una perseverancia que a veces me asombra y abierto a las nuevas lecciones que se puedan aprender en el día a día.

Ustedes, estudiantes de arquitectura, tienen toda una vida por delante, qué hacer con ella, he ahí la cuestión. A lo largo de este evento académico han escuchado detenidamente diversas posturas, distintos caminos, ya ustedes decidirán cuales tomar, de mi parte no he querido catequizarlos, pero sí, mostrarles que hay nuevas puertas por abrir en un escenario complejo que seguramente exigirá mucho de ustedes, y también, a muchos de ustedes, para llegar a aportar desde la disciplina a la construcción de un país más justo, de una ciudad más equitativa, y ojalá, de una sociedad más equilibrada. La arquitectura debe estar necesariamente ahí, en el diseño y construcción de estos nuevos escenarios, de la mano con otras disciplinas de las cuales debe dejarse permear.

Siendo optimistas, en el escenario del post conflicto que se nos viene en los próximos años, estos temas estarán aún más presentes en la agenda del día, y no vamos a poder evadirlos. Y no solo habrá que intervenir en los territorios rurales, las ciudades y en especial sus barrios populares, entrarán a jugar parte importante de esta construcción de un mejor país, ya cansado de

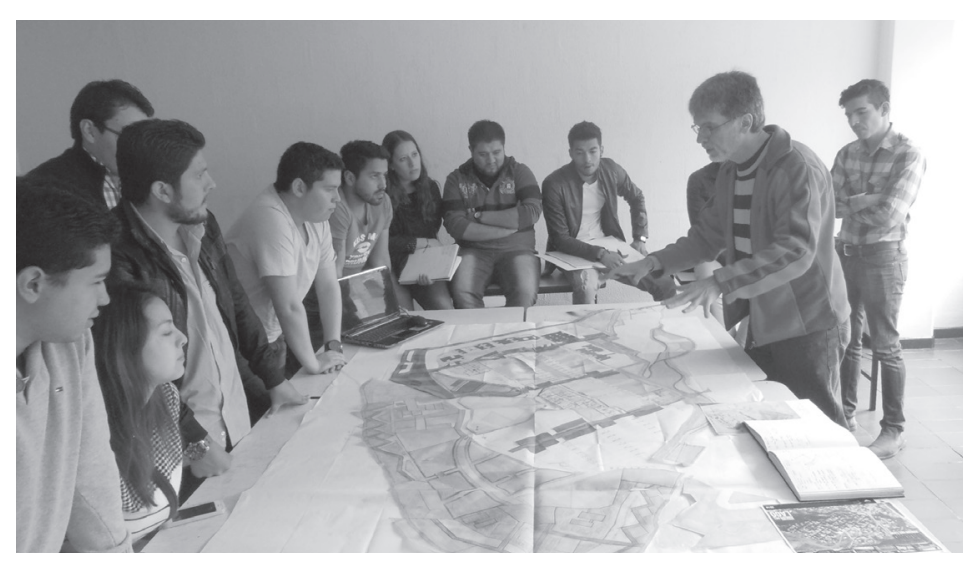


guerras e injusticias, de inequidad y de violencia, y llegará el momento de la proposición, y desde ya debemos comprometernos para que no nos encuentren con las manos vacías.

Estudiantes de arquitectura, estas ciudades y este país real, sin maquillajes ni artilugios, espera mucho de ustedes, de todos nosotros. No olviden que allá afuera hay un mercado casi salvaje por enfrentar, pero también, muchos ideales por construir que desde nuestra disciplina, incluida su ética y su estética, deberán retomar como agenda a atender cotidianamente, sea cual sea el camino que escojan, tómenlo como bandera, como sueños por construir.

\section{Referencias bibliográficas}

Avendaño, F. \& Carvajalino, H. (1985). "Modelo teórico práctico de participación comunitaria en el diseño". Documento de uso interno de la Facultad de Arquitectura de la Universidad La Gran Colombia (sin publicar), Bogotá, noviembre de 1985.

Avendaño, F. \& Carvajalino, H. (2003). "Vivienda popular espontánea: conceptos de espacialidad y progresividad. Reflexiones a partir de un estudio de caso: Bogotá, Colombia". Revista Ciudad y territorio, estudios territoriales, XXXV, pp. 136-137. Madrid (España).

Borja, J. \& Castell M. (1999). Local y global. Editorial Taurus, Madrid.

Carvajalino, H. (2005). "Hábitat popular y programas de mejoramiento: Intervenir escenarios en proceso de consolidación". Revista INVI 53 de la Universidad de Chile, Santiago de Chile.

Carvajalino, H. (2006). "Sobre rombos y otros motivos populares". Revista Alarife, número 13 de la Universidad Piloto de Colombia. Bogotá, D. C.

Carvajalino, H. (2010). "Panel antropológico y social" (pp.195 a 200), En: Arrendamiento y vivienda popular como alternativa habitacional, de la Mesa VIS de la Universidad de Los Andes, Bogotá, D. C.
Carvajalino, H. (2013). "Aprendiendo del barrio La Paz, un escenario desde el cual vincular la academia a esta otra arquitectura". Revista Arquitectura, volumen 15, de la Facultad de Diseño de la Universidad Católica de Colombia.

Carvajalino, H. (2000). “Urbanismo, arquitectura y participación popular”. Tesis para obtener el título de Mágister en Urbanismo, Universidad Nacional de Colombia, Bogotá, D. C.

Goodman, R. (1977). ¿Después de los urbanistas $q u e ́$ ? Editorial Blume, Madrid.

Mendoza, M. (octubre de 2007). "La ciudad jamás contada”. En: Diario El Tiempo, Bogotá, D. C.

Montaner, J. M. (2004). "Traumas urbanos: La pérdida de la memoria. Centro de cultura contemporánea de Barcelona", conferencia pronunciada en el marco del debate Traumas urbanos: la ciudad y los desastres.

Pezeu-Massabuau, J. (1988). La vivienda como espacio social. Fondo de Cultura Económica, Ciudad de México.

Secretaría Distrital del Hábitat (2008). Informe técnico de soporte de la Política Integral del Hábitat, 2007-2017. Bogotá, D. C.

Serie Ciudad y Hábitat (1995). "PMV. A mejorar lo construido". Número 1, Documentos Barrio Taller, Santa Fe de Bogotá, D.C.

Serie Ciudad y Hábitat (1996). "Una mirada a la periferia”. Número 2, Documentos Barrio Taller, Santa Fe de Bogotá, D.C.

Serie Ciudad y Hábitat (1996). "La casa: Conceptos de espacio y de vida". Número 3, Documentos Barrio Taller, Santa Fe de Bogotá, D.C.

Serie Ciudad y Hábitat (2000). "Espacialidad de la periferia”. Número 8, Documentos Barrio Taller, Bogotá, D.C.

Serie Ciudad y Hábitat (2004). "Expresión formal de la vivienda espontanea”. Número 11, Documentos Barrio Taller, Bogotá, D.C.

Turner, J. (1977). Vivienda, todo el poder para el usuario. Hacia la economía de la construcción del entorno. Madrid: $\mathrm{H}$. Blume editor. 